\title{
QUADRO GEOLÓGICO REGIONAL DA PORÇÃO CENTRAL DO EMBASAMENTO PRÉ-ORDOVICIANO DE SANTA CATARINA COM BASE EM IMAGENS LANDSAT-5/TM E AEROGEOFÍSICAS
}

\author{
NEIVALDO ARAUJO DE CASTRO ${ }^{1}$, ALVARO PENTEADO CRÓSTA ${ }^{2}$ \\ FRANCISCO JOSÉ FONSECA FERREIRA ${ }^{3}$, MIGUEL A. S. BASEI ${ }^{1} \&$ \\ MARIA ELISABETE PASCHOLATI ${ }^{2}$
}

\begin{abstract}
GEOLOGIC FRAMEWORK OF THE CENTRAL PORTION OF THE PRE-ORDOVICIAN BASEMENT OF SANTA CATARINA USING LANDSAT-5/TM AND AEROGEOPHYSICAL IMAGES This paper presents the results of a comparative analysis between litho-structural features observed in LANDSAT-5/TM and aerogeophysical images, in comparison with the regional geological framework of the central portion of the pre-Ordovician basement in the Santa Catarina state (EPOSC), southern Brazil. This is a lithological and structurally complex region, due to the geotectonic evolution of western Gondwana during the Neoproterozoic/Cambrian transition and the break-up of this supercontinent during the Mesozoic. LANDSAT-5/TM imagery contributed with relevant information on brittle structures, whose genesis is probably related to thermal-tectonic events of the formation and break-up of Gondwana. Interpretation of geophysical data (gamma-ray and magnetics) allowed the recognition of features associated with major lithologic units and their structures. The results showed that the integrated analysis of these data contributes to the advance of geological knowledge of this region and, in some cases, provides detailed information for geological cartography.
\end{abstract}

Keywords: remote sensing, aeromagnetometry, aerogammaspectrometry, Santa Catarina, Gondwana.

Resumo Este trabalho apresenta os resultados da análise comparativa entre as feições litoestruturuais observadas em imagens LANDSAT-5/TM e aerogeofísicas frente ao quadro geológico regional da porção central do embasamento pré-Ordoviciano do Estado de Santa Catarina (EPOSC). Trata-se de uma região com acentuada complexidade litológica e estrutural, decorrente principalmente do cenário geotectônico gerado pela amalgamação final do Gondwana Ocidental durante a transição Neoproterozóico/Cambriano e, em menor proporção, pela fragmentação deste supercontinente durante o Mesozóico. As imagens LANDSAT-5/TM contribuíram com informações relevantes sobre as estruturas rúpteis, cuja gênese é provavelmente vinculada aos eventos tectono-termais atuantes na formação e dispersão do Gondwana na região. Adicionalmente, os dados aerogeofísicos (gamaespectrometria e magnetometria) permitiram reconhecer feições associadas aos grandes conjuntos litológicos e seus padrões estruturais. Os resultados obtidos mostram que a análise integrada desses dados é capaz de contribuir para o aprimoramento do quadro geológico regional conhecido e, em alguns casos, até mesmo fornecer um detalhamento da cartografia existente.

Palavras-chave: sensoriamento remoto, aeromagnetometria, aerogamaespectrometria, Santa Catarina, Gondwana.

INTRODUÇÃO O emprego conjunto de imagens orbitais de sensoriamento remoto e aerogeofísicas tem fornecido, sobretudo a partir da última década, uma importante ferramenta no mapeamento de feições lito-estruturais regionais e, notadamente em regiões pouco conhecidas.

Imagens de sensoriamento remoto podem fornecer dois tipos de informações geológicas. O primeiro refere-se a informações de natureza espectral, ligadas à composição química das rochas e materiais destas derivados. O segundo engloba informações de natureza textural e estrutural, impressas nas formas de relevo, indicadoras tanto da composição litológica como das estruturas geológicas presentes no substrato. Em regiões cobertas por vegetação e/ou com presença de atividades antrópicas, as informações espectrais são geralmente de difícil obtenção. Por outro lado, as informações texturais e estruturais são função do relevo e independem da presença ou ausência de vegetação. Nessas regi- ões, a interpretação geológica a partir de elementos texturais pode fornecer informações sobre diferentes domínios litológicos e estruturais. Dadas as características da área enfocada neste trabalho, alternando regiões com densa cobertura vegetal e outras intensamente afetadas por atividades antrópicas, foram consideradas unicamente informações estruturais extraídas a partir das imagens orbitais utilizadas.

Dados aerogeofísicos (gamaespectrométricos e magnetométricos) fornecem informações sobre o comportamento regional, em superfície e sub-superfície. A eficácia da interpretação geológica destes dados depende da resolução espacial e da qualidade de cada levantamento.

Neste trabalho, procura-se mostrar que, apesar das limitações impostas pela resolução e pela qualidade dos dados de sensoriamento remoto e aerogeofísicos disponíveis, estes são capazes de fornecer informações úteis na análise das feições geo-

\footnotetext{
1 - IGC-USP, Rua do Lago 562, CEP 05508-900, São Paulo-SP, neivaldoc@bol.com.br, baseimas@usp.br

2 - IG-UNICAMP, caixa postal 6152, CEP 13083-970, Campinas-SP, alvaro@ige.unicamp.br, paschol@ige.unicamp.br

3 - UFPR, caixa postal 19001, CEP: 81531-990, Curitiba-PR, francisco.ferreira@ufpr.br
} 
lógicas regionais presentes na porção central do embasamento pré-Ordoviciano de Santa Catarina-EPOSC (Fig. 1).

CONTEXTO GEOLÓGICO A geologia do EPOSC pode ser abordada a partir de dois aspectos principais. Um corresponde às
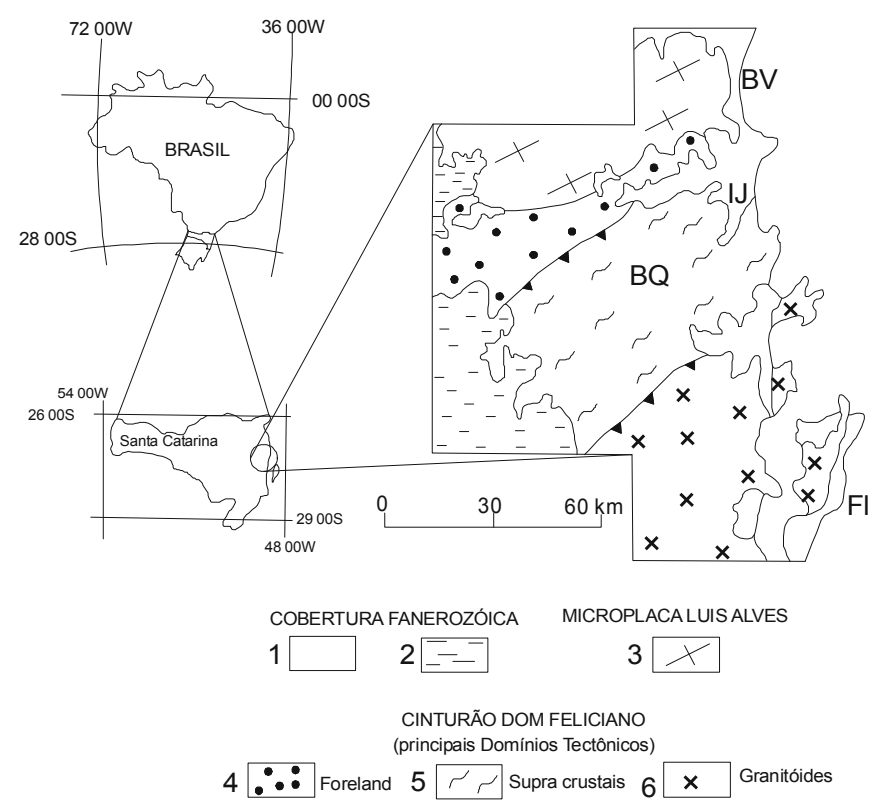

Figura 1 - Localização e contexto geotectônico do Cinturão Dom Feliciano e Cráton Luis Alves, porção central do EPOSC. Cobertura Cenozóica-1; Paleozóico, Bacia do Paraná-2; Microplaca Luis Alves-3; Cinturão Dom Feliciano, domínios Foreland-4, Supracrustal-5 e Granitóides-6.

feições geradas durante a transição Neoproterozóico/Cambriano, envolvendo o Cinturão Dom Feliciano (CDF) e seu antepaís (Microplaca Luis Alves-MLA) na formação do Gondwana ocidental. O outro diz respeito à reativação mesozóica, responsável pelo rifteamento precursor do oceano Atlântico Sul.

Um número expressivo de trabalhos geológicos foram realizados na região, iniciados pelo pioneirismo de Carvalho e Pinto (1938), os quais apontaram a existência da Série Brusque (filitos, quartzitos e mármores que ocorrem próximo à localidade homônima). Seguiram-se os trabalhos de Trainini et al. (1978), Basei (1985), Mantovani et al. (1987), Siga Jr. et al. (1990), Rostirolla et al. (1992), Hallinan e Mantovani (1993), Caldasso et al. (1994 a,b), Passarelli (1996), Castro (1997), Castro et al. (1997) e Hartmann et al.(1998). Os eventos tectono-termais colisionais relacionados à aglutinação do Gondwana são mencionados nos trabalhos de Soares (1988), Trompette (1997), Basei et al. (2000). Apresenta-se a seguir as principais características do EPOSC com base em Basei et al. (2000).

Neste embasamento, destaca-se a seqüência vulcano-sedimentar do Grupo ou Complexo Brusque (GCB), a qual foi deformada e metamorfizada no Brasiliano, em um primeiro evento colisional. Posteriormente, um segundo evento orogenético (Rio Doce), com vergência para NW, deformou inclusive os sedimentos mais jovens do Grupo Itajaí depositados na região foreland do CDF, colocando as litologias situadas mais a SE sobre os terrenos granulíticos da MLA.
Para Basei et al. (2000), esse evento evoluiu da seguinte forma: 1) metamorfismo nas rochas do GCB, com transporte tectônico para NW, em torno de $700 \pm 50 \mathrm{Ma} ; 2$ ) evento colisional em torno de $640 \pm 20 \mathrm{Ma}$, com o desenvolvimento de granitóides deformados associados à zona de cisalhamento Major Gercino (ZCMG); 3) sedimentação no domínio foreland (Grupo Itajaí, GI) há cerca de $560 \pm 20 \mathrm{Ma}$; 4) evento colisonal final com vergência para NW, deformador do GI ( $535 \mathrm{Ma})$. Durante essa evolução, a colagem tectônica dos diferentes domínios do CDF foi balizada pelas zonas de cisalhamento ZCMG e Faixa Ribeirão da Prata (ZCFRP), que teria acomodado a maior parte da deformação associada ao evento Rio Doce.

Principais domínios tectônicos O EPOSC apresenta dois domínios tectônicos principais (Figs. 1 e 2): o Cinturão Dom Feliciano (CDF) e a Microplaca Luis Alves. Essa compartimentação regional tem continuidade no Rio Grande do Sul e Uruguai, na forma de um cinturão de dobramentos com cerca de 1500 km de extensão.

A MLA é limitada a norte pela zona de sutura de Piên (Paraná) e a sul pelos núcleos de gnaisses deformados da ZCFRP. As idades $\mathrm{U}-\mathrm{Pb}$ encontram-se entre 2,35 e 2,012 Ga e os valores K-Ar muito próximos de $2,0 \mathrm{Ga}$, atestando que não houve reativações termais após o Paleoproterozóico. Nesse domínio, predominam gnaisses granulíticos de composição charno-enderbíticas e rochas máficoultramáficas.

O CDF é subdividido em Santa Catarina, de noroeste para sudeste, nos Domínios Foreland (Grupo Itajaí), Supracrustal (Grupo ou Complexo Brusque, GCB) e cinturão Granitóide (Batólito de Florianópolis, BF). Nas figuras 1 e 2 pode ser observada a sua disposição espacial.

O Grupo Itajaí ocupa uma área de mais de $700 \mathrm{~km}^{2}$, alongada segundo a direção N60E, acompanhando o curso do Rio Itajaí (Fig. 2). Ele abrange uma espessa pilha sedimentar composta por seqüência basal de conglomerados, arcóseos e arenitos, e sequência de topo com turbiditos de afinidade marinha. $\mathrm{O}$ magmatismo da suíte plutono-vulcânica Subida, que intrude os constituintes do GI, apresenta uma idade mínima em torno de 560 Ma (Basei et al.1999).

O Grupo Brusque (GCB) é constituído por uma associação vulcano-sedimentar metamorfizada em diferentes graus e intrudida por granitóides (Fig. 2). Subordinadamente, ocorrem núcleos gnáissico-migmatíticos do embasamento. O volume de granitóides intrusivos no GCB é expressivo (até 50\% de todo o DSC). Os granitóides ocorrem sob a forma de dois batólitos, com destaque para o batólito Valsungana a sul, com eixos paralelos aos limites do GCB e, em menor proporção, como stocks. A maioria desses granitóides é de filiação cálcio-alcalino. Análises isotópicas de $\mathrm{Sm}-\mathrm{Nd}, \mathrm{Rb}-\mathrm{Sr}$ e U-Pb indicam a presença de granitóides gerados entre $640 \mathrm{Ma}$ e $570 \mathrm{Ma}$, tendo como provável protólito uma crosta continental de idade paleo-Proterozóica (2.100 Ma a 1.800 Ma).

O Domínio Granitóide apresenta idades modelo $\mathrm{Sm}-\mathrm{Nd}$ ao redor de 1.500 Ma para o magmatismo (gerado entre 644 e $590 \mathrm{Ma}$ ). Os granitóides mais antigos são foliados, com composições granodioríticas a monzograníticas, subordinadamente dioritos até gabros, todos de afinidade cálcio-alcalina. Ocorrem também porções menos deformadas, quartzo-dioríticas, granodioríticas e monzoníticas. Os granitóides mais jovens associam-se às vulcânicas ácidas, apresentam afinidade alcalina, são isótropos e demonstram composição entre monzo e sienogranítica. Pelas informações disponíveis, o DG representa as raízes de um arco magmático Neoproterozóico com gênese atribuída a um processo de 


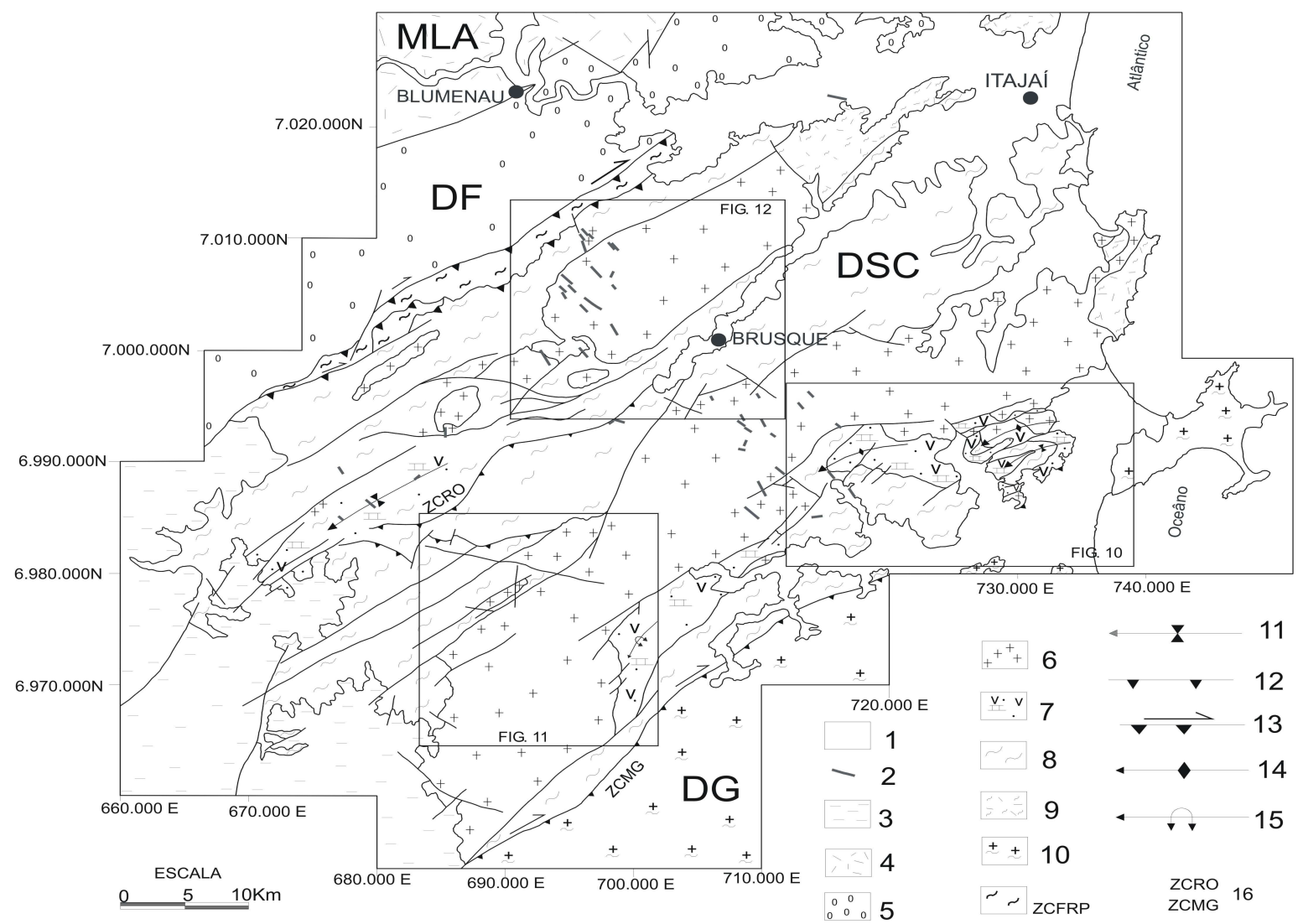

Figura 2 - Principais feições geológicas da porção central do EPOSC. 1 - Cobertura cenozóica. 2 - Diques básicos pré-Ordovicianos e Mesozóicos. 3 - Paleozóico, Bacia do Paraná. 4 - Microplaca Luis Alves (MLA). Cinturão Dom Feliciano, domínios: 5 - Foreland, Grupo Itajaí; 6 - Supracrustal: granitóides intrusivos. Grupo ou Complexo Brusque: 7 - associação vulcano-sedimentar, 8 - associação pelito-arenosa, 9 - núcleos de embasamento; 10 - cinturão Granitóide. Elementos estruturais: 11 - sinformes, 12 - empurrões, 13 - transpressão, 14 - antiformes, 15 - antiformes com flanco invertido, zonas de cisalhamento: Faixa Ribeirão da Prata (ZCFRP), Major Gercino (ZCMG), Ribeirão do Ouro (ZCRO).

subducção do tipo B, de NW para SE. Apesar do considerável volume de crosta oceânica envolvida nesse processo, esses granitóides também exibem grande contribuição de crosta continental em sua gênese, indicando a proximidade da porção cratônica situada a E-SE (Cráton do Kalahari).

O evento Mesozóico (abertura do oceano Atlântico sul) O rifteamento que originou o oceano Atlântico Sul no Mesozóico foi responsável pela geração e reativação de estruturas em grande parte do território brasileiro (Fig. 3). Pormenores sobre essa reativação podem ser encontrados em Burke \& Dewey (1973), Almeida (1986), Conceição et al. (1988), Ferreira (1982), Piccirillo et al. (1989), Renne et al. (1992), Szatimari \& Milani (1999).

O processo precursor do rifteamento é atribuído ao aquecimento provocado por uma pluma mantélica quente, capaz de gerar uma junção tríplice que desencadeou a ruptura litosférica. Renne et al. (1992) postulam que o calor pode ter se originado da pluma de Tristão da Cunha, hoje situada no interior do oceano Atlântico Sul. Neste contexto, a região do Arco de Ponta Grossa representa o braço abortado dessa junção tríplice, o qual não evoluiu para uma bacia sedimentar, mas encerrou um enxame de diques básicos e serviu de conduto para as lavas da Formação Serra Geral.

$\mathrm{O}$ evento Mesozóico manifesta-se por meio de diques básicos situados nos três domínios do $\mathrm{CDF}$, com direção predominante N45W, a qual secciona a porção central do CDF (Fig. 2). A sul, há a ocorrência de diques básicos de direção N5-10E, situados na ilha de Florianópolis e a NE da localidade de Tubarão. Dois corpos alcalinos são identificados no domínio do CDF em Santa Catarina: um a sul da localidade de Botuverá e o outro a norte de Anitápolis (Domínio Granitóide do CDF, a sul da região estudada). Intrudindo rochas sedimentares da Bacia do Paraná destaca-se a intrusão de Lages, a maior manifestação alcalina mesozóica do estado de Santa Catarina.

Ferreira et al. (1989), estudando os depósitos de fluorita de Santa Catarina, indicam um controle por lineamentos identificáveis em imagens LANDSAT-5/TM, de direção N10E (subordinadamente $\mathrm{N} 60 \mathrm{E}$ ). Tais lineamentos teriam sido originados em sistemas transcorrentes pré-Cambrianos e reativados no Mesozóico. Nessa época, foram geradas importantes concentrações de fluorita, com barita subordinada, a partir de sistemas convectivos concentrados em regiões de fraqueza durante o rifteamento Mesozóico. É interessante notar que, na direção N10E, também ocorrem zonas de gnaisses e de milonitos dúcteis mais antigas, sugerindo que a instalação dos veios fluoríticos obedeceu a estruturas prévias. A reativação de estruturas foi constatada pelas idades K-Ar obtidas em frações finas da ZCMG ( 220 Ma, Passarelli 1996). 


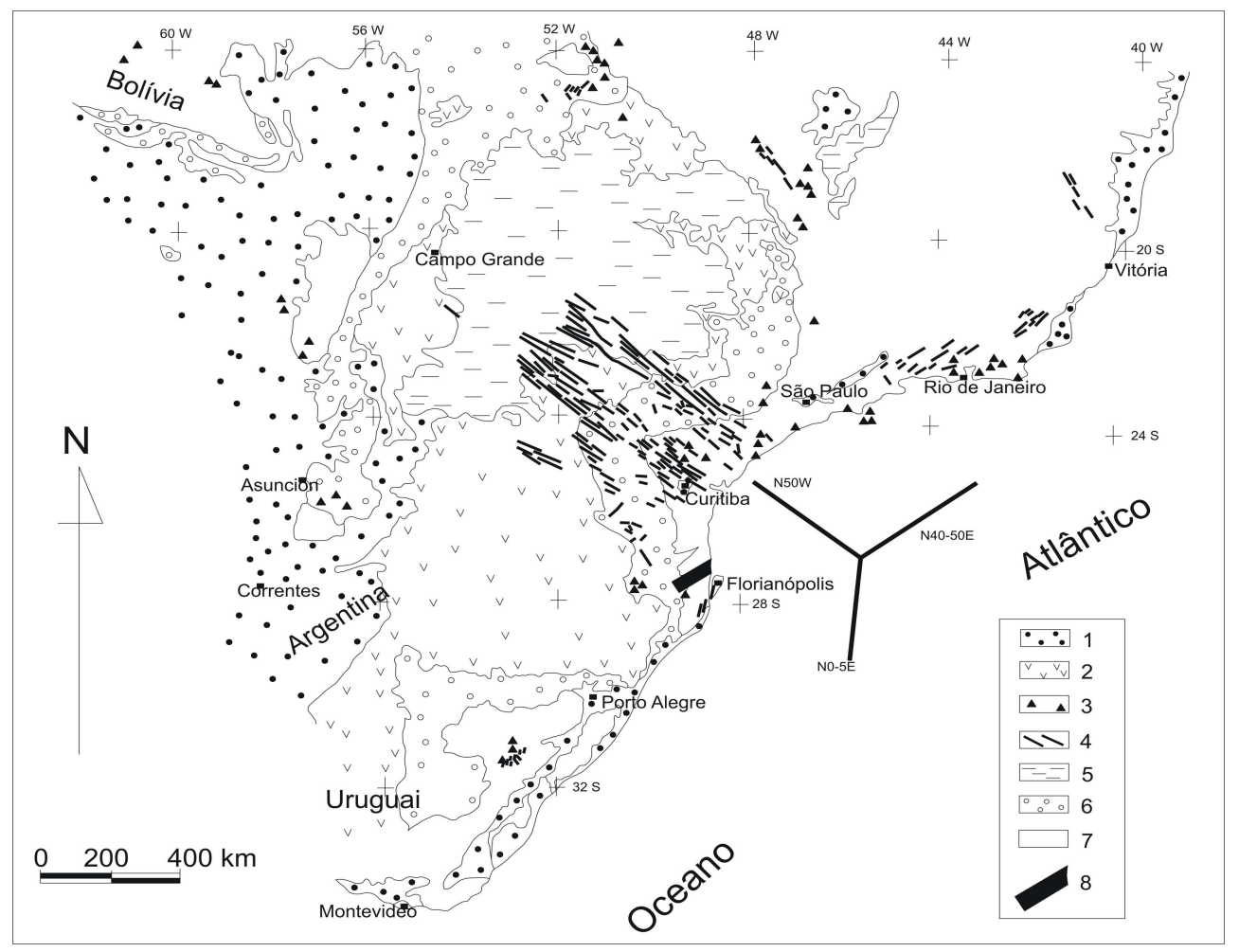

Figura 3 - Principais feições geológicas associadas ao rifteamento responsável pela instalação do Atlântico Sul no Mesozóico. Corpos alcalinos-1, Diques básicos-2, Cobertura cenozóica-3, Cobertura mesozóica-4, Derrames basálticos-5, Cobertura paleozóica6, Embasamento pré-Ordoviciano-7, Área de estudo-8. Adaptada de Piccirillo et al. (1989).

INTERPRETAÇÃODASIMAGENSLANDSAT-5/TM Aanálise das imagens LANDSAT/TM foi orientada para a extração de feições estruturais impressas no relevo. Para tanto, foram empregadas técnicas de processamento objetivando o realce de lineamentos, tais como filtragens e análise por principais componentes. Maiores detalhes sobre as técnicas mencionadas podem ser encontradas em Crósta (1993) e Drury (2001).

Características e processamento De modo geral, a morfologia do terreno possui relação com as características litoestruturais do substrato rochoso. Desse modo, lineamentos expressos pelas formas superficiais de relevo podem ser utilizados na identificação de feições estruturais, tais como falhas, fraturas e foliação (Hobs 1912, apud Thomas 1974). A utilização de imagens de sensoriamento remoto facilita e intensifica o uso dos lineamentos como elementos de análise estrutural (Thomas 1974, Soares \& Fiori1976, Liu1984, Ferreira et al.1989, Rostirolla et al.1992, Amaral 1994, Castro1997).

Soares \& Fiori (1976) denominam de elementos texturais de relevo positivo ou negativo à menor superfície contínua e passível de repetição em uma imagem. Nesse trabalho adota-se a designação genérica de "lineamento", segundo Hobs (1912, apud Thomas 1974), para designar feições lineares impressas no relevo, as quais são capazes de fornecer informações sobre o arcabouço lito-estrutural de uma região. Em complemento, lineamentos representam toda feição natural linear ou levemente anastomosada, expressa em várias escalas de observação, associada ao relevo negativo ou positivo de uma região (cristas, encostas, vales, etc).

Um aspecto a se levar em conta quando da identificação e traça- do de lineamentos é a característica de iluminação natural durante a aquisição de uma imagem. Liu (1984) discute tal aspecto, apontando a variação sazonal da inclinação da iluminação solar de acordo com as épocas do ano (por exemplo, $\sim 50^{\circ}$ no verão e $\sim 25^{\circ}$ no inverno para a região sudeste do Brasil). As baixas inclinações devem ser preferidas para estudos em regiões de relevo pouco acidentado, enquanto as altas devem ser utilizadas em trabalhos de análise espectral ou estrutural em regiões de relevo acidentado. Variações direcionais da iluminação (azimute solar) devem também ser consideradas. Tal fator tende a provocar um maior destaque dos lineamentos ortogonais à direção de iluminação (Crósta 1993, Liu 1984).

A imagem LANDSAT-5/TM utilizada, correspondente à órbitaponto 220/79 (WRS), coletada em julho de 1994, possui iluminação segundo um azimute em torno de $225^{\circ}$ e inclinação próxima a $25^{\circ}$. Deste modo, os lineamentos de direção NW são mais fácilmente detectáveis em relação às demais direções.

O pré-processamento consistiu no geo-referenciamento segundo o sistema de coordenadas UTM (datum Chuá, Zona 22 Sul), implementado através de 31 pontos de controle identificados tanto nas imagens como nas cartas do Instituto Brasileiro de Geografia e Estatística-IBGE) na escala 1:50 000. Todos os pontos de controle utilizados mostraram erros inferiores a $30 \mathrm{~m}$.

$\mathrm{O}$ realce dos lineamentos foi feito por meio de técnicas de aumento de contraste, análise de bandas isoladas (preferencialmente bandas 4, 5 e 7), composições coloridas RGB utilizando as bandas 3, 4, 5 e 7 e cálculo da primeira componente principal (PC1) sobre as bandas 1, 2, 3, 4, 5 e 7. Eventualmente, em regiões onde lineamentos com determinadas direções encontravam-se obscu- 
recidos, foram utilizados filtros direcionais. A identificação e traçado dos lineamentos foi feito interativamente no monitor do sistema de processamento. $\mathrm{O}$ traçado foi feito de acordo com escalas locais e regionais, representadas, respectivamente, pelos interva$\operatorname{los} 1: 50000-1: 1000000$ e 1:150000-1:250 000. A identificação, traçado, análise estatística descritiva direcional e do comprimento dos lineamentos foi feita por meio do programa Lineament Analysis Wizard for ER Mapper, que apresenta o conjunto de lineamentos em diagrama de rosetas com classes angulares em intervalos definidos pelo usuário, além de fornecer as características de cada classe ( número de elementos, comprimentos associados, etc).

Resultados As feições estruturais mais notáveis da região de estudo são expressas nos lineamentos interpretados a partir da imagem PC1, mostrados nas figuras 4 e 5, nos intervalos de escalas respectivamente de 1:50 000 - 1:100 000 e 1:150 000 - 1:250 000 . Nelas, observa-se alta densidade de lineamentos de relevo negativo, dispostos segundo os intervalos N00-05E, N65-75E, N4045W e N70-85W. Destaca-se ainda o curso do Rio Itajaí, balizado por estruturas nas direções N65-75E e N40-45W. Outro aspecto notável é a disposição em torno da direção N45E do depósito aluvial associado ao Rio Itajaí Mirim (porção NE). Conforme será visto adiante, tal disposição está provavelmente relacionada à estruturação mais antiga presente nas litologias do GCB.

As principais feições estruturais do CDF (ZCFRP, ZCMG, ZCRO e alguns eixos de dobras geradas por colisão durante a orogênese
Rio Doce) e o limite leste da Bacia do Paraná (BP) são nitidamente expressos nesses mapas de lineamentos. As mesmas direções preferenciais foram identificadas também nos sedimentos da Bacia do Paraná, nos dois intervalos de escala acima mencionados.

A estatística direcional dos lineamentos nas escalas consideradas, em intervalos de cinco graus, é mostrada em diagramas de rosetas (Figs. 4 e 5c). Além das principais direções, as características de cada intervalo foram analisadas em termos de seus constituintes e comprimentos associados. Salvo uma maior dispersão das modas consideradas, o mesmo padrão de distribuição (intervalos direcionais: N00-05E, N65-75E, N40-45W e N75-85W) pode ser observado nas várias escalas consideradas. Nas figuras 6, 7,8 e 9 são mostrados alguns detalhes sobre o modo de ocorrência dos lineamentos nesses intervalos direcionais.

A comparação desses lineamentos com as feições geológicas regionais do EPOSC permitiu constatar que, na porção SE do DSC, existe uma associação de certos lineamentos com a superfície metamórfica principal das supracrustais (Fig. 6). Como exemplo, cita-se a oeste do Rio do Oliveira, onde os lineamentos N70W coincidem com a direção da principal estrutura metamórfica do DSC, situada no flanco sul de uma estrutura antiformal e provavelmente nucleada durante o evento colisional Rio Doce.

Os lineamentos pertencentes aos demais intervalos direcionais parecem estar associados à fase compressiva da orogênese Rio Doce. Durante esse evento, os esforços responsáveis pelas falhas de empurrão com imbricamento tectônico na ZCFRP, envol-

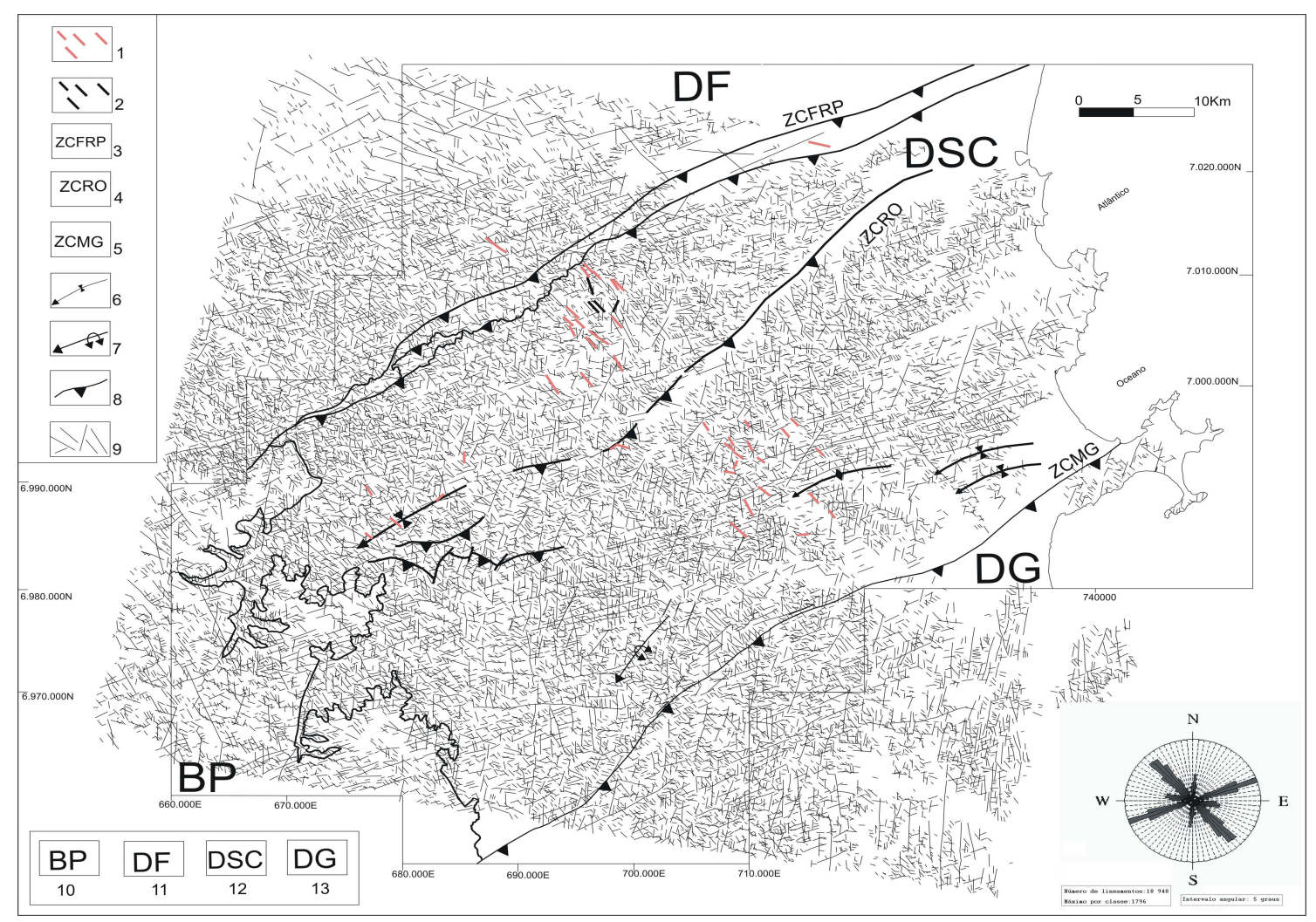

Figura 4 - Mapa de lineamentos de relevo negativo extraido da imagem LANDSAT-5/TM no intervalo 1:50.000 a 1:100.000. Diques básicos Mesozóicos-1; Diques básicos eo-cambrianos-2; Zonas de cisalhamento: Faixa Ribeirão da Prata-3, Ribeirão do Ouro-4, Major Gercino-5; Antiformes-6, Antiformes com flanco invertido-7; Empurrões-8; Lineamentos de relevo negativo-9; Bacia do Paraná-10; Cinturão Dom Feliciano, domínios Foreland -11, Supracrustal-12, Granitóides-13. O diagrama de rosetas na parte inferior direita mostra a distribuição estatística dos diferentes lineamentos identificados. 


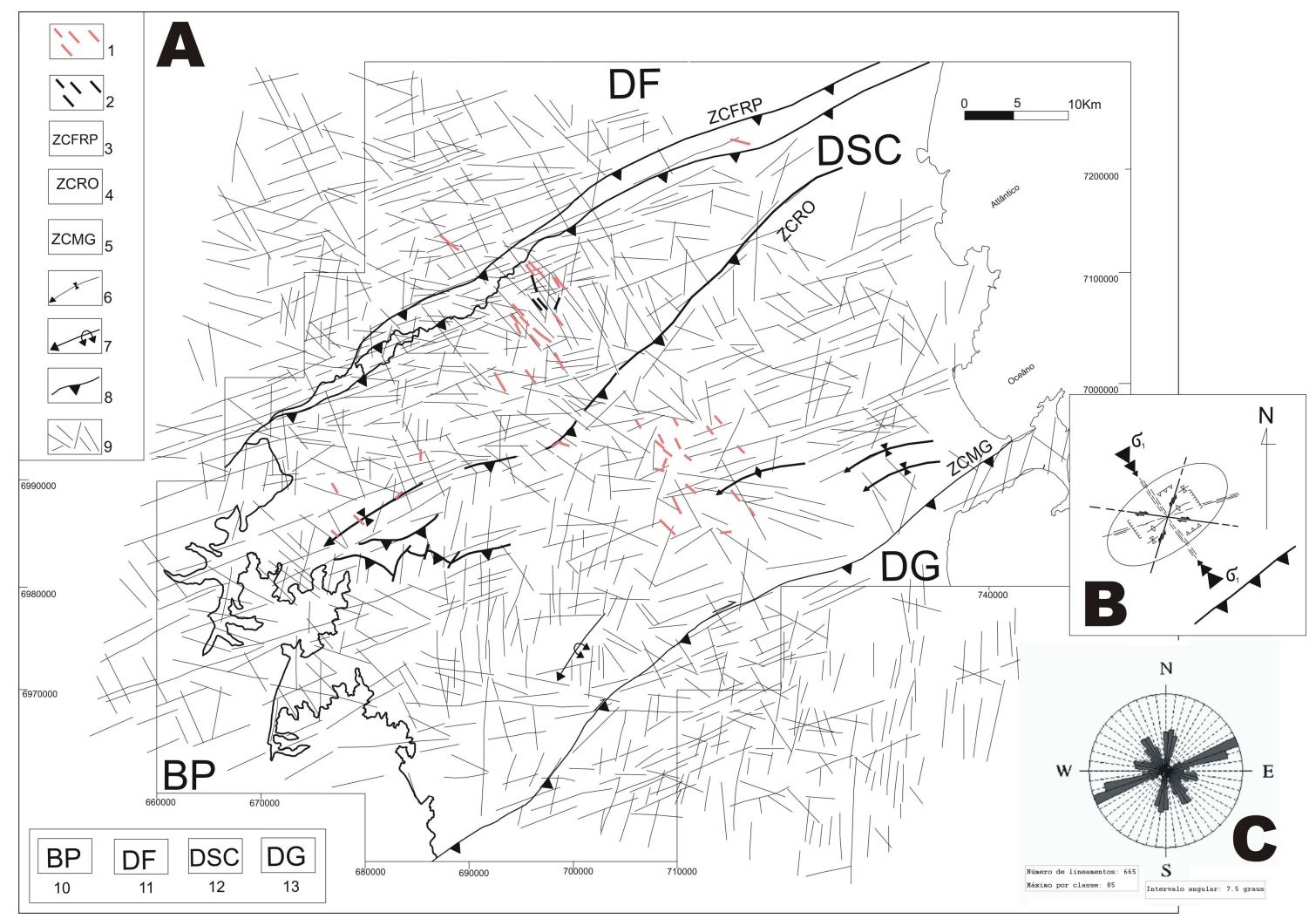

Figura 5 - A - Mapa de lineamentos de relevo negativo extraído da imagem LANDSAT-5/TM no intervalo 1:150 000 e 1:250 000. Legenda igual à da Figura 4. B - estrutruras associdas ao provável elipsóide de deformação vigente durante a orogênese Rio Doce (adaptado de Harding,1974). C - Diagrama em roseta para os lineamentos identificados no intervalo de escala abordado.

vendo os domínios DSC e DF, teriam permitido a geração de várias estruturas secundárias, tais como dobras, transcorrências e fraturas distensivas. $\mathrm{O}$ elipsóide de deformação apresentado na figura 5 b procura explicar essa relação. De acordo com a relação estabelecida, os diferentes intervalos direcionais apresentam correlação espacial com as seguintes estruturas presentes no elipsóide: a) N00-05E: trancorrências sinistrais (Fig. 7); b) N6575E: fraturas de cisalhamento (Fig. 6); c) N75-85W: transcorrências dextrais (Fig. 6); d) N40-45W: fraturas distensivas paralelas ao esforço principal (Fig. 8).

A figura 9 mostra exemplos da continuidade das estruturas NE mais antigas por sob os sedimentos da Bacia do Paraná, fato este já constatado na literatura e tido como importante para a evolução desses sedimentos. Cordani et al. (1984) destacaram a influência de eventos Pré-cambrianos na evolução dos sedimentos Fanerozóicos brasileiros. Soares (1992) concluiu que a reativação de estruturas presentes no embasamento da Bacia do Paraná desempenhou importante papel nos processos formadores e deformadores desses sedimentos. Analisando imagens LANDSAT-5/TM e de radar (RADAMBRASIL) este autor observou que a direção da maioria dos lineamentos observados na Bacia do Paraná coincide, ou está próxima, daquelas presentes em seu embasamento aflorante. Milani e Thomaz Filho (2000) também ressaltaram a importância da estruturação Pré-Cambriana na evolução fanerozóica desses sedimentos. O presente trabalho traz mais evidências de que o legado estrutural Brasiliano-Rio Doce encontra-se registrado na pilha sedimentar da Bacia do Paraná e deve ter influenciado sua deposição e deformação.

Atenção especial foi dada aos lineamentos orientados segundo os intervalos N00-05E e N40-45W. De acordo com o modelo de junção tríplice responsável pela fragmentação do Gondwana e instalação do Atlântico Sul, tais lineamentos devem ter sido reativados segundo esforços trativos expressivos. A validade dessa relação é sugerida na região leste-sudeste do CDF pela ocorrência de veios fluoríticos com barita e diques básicos de idade mesozóica dispostos, respectivamente, nessas direções.

INTERPRETAÇÃODAS IMAGENSAEROGEOFÍSICAS Os dados aerogeofísicos, originalmente na forma de linhas de vôo, foram convertidos para malhas regulares, a partir das quais foram geradas imagens. As variáveis do campo magnético residual, contagem total (CT), Potássio (K), Urânio (eU) e Tório (eTh) foram tratadas conforme técnicas apresentadas por Ferreira (1982), Yeates et al. (1982), Gunn et al. (1997), Horsfall (1997), Luyendyk(1997), Milligan \& Gunn (1997), Minty et al. (1997), Reeves et al. (1997), MacLeod \& Dobush (2000).

Características e processamento Foram utilizados os dados do projeto aerogeofísico Serra do Mar Sul (GEOFOTO 1978). Os principais parâmetros do levantamento são: 1) linhas de vôo com direção N30W, espaçadas de $1.000 \pm 250 \mathrm{~m}$; 2) intervalo de amostragem ao longo das linhas $\sim 60 \mathrm{~m} ; 3$ ) altura nominal de vôo de $150 \pm 50 \mathrm{~m}$; 4) gamaespectrometria - contagem total, eTh, eU e $\mathrm{K}$, em contagens por segundo (cps), corrigida do background 


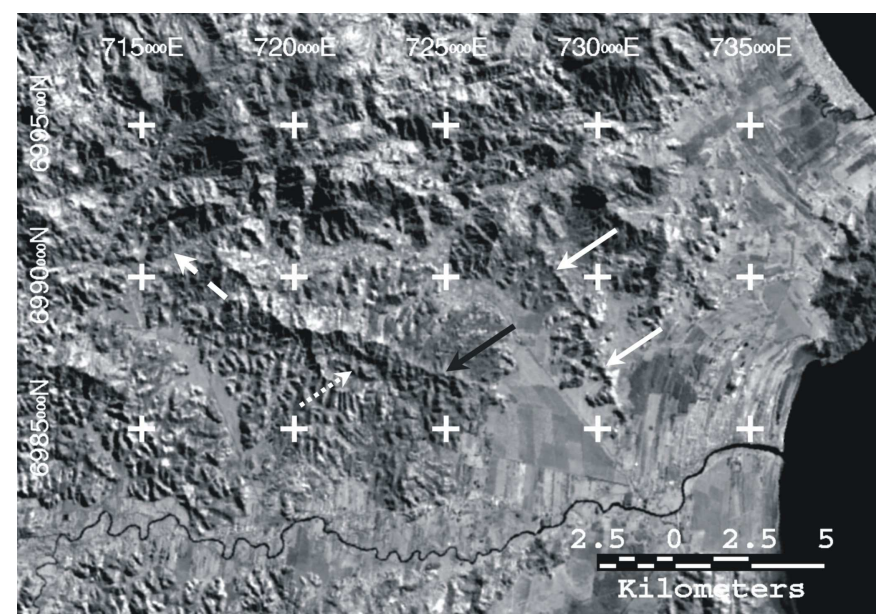

Figura 6 - Imagem PC1 da região do Rio do Oliveira, porção SE do domínio supracrustal do Cinturão Dom Feliciano. A seta escura indica um lineamento de relevo positivo de direção N70$85 \mathrm{~W}$, cercado por lineamentos de relevo negativo de mesma direção (seta pontilhada). Esta é a direção da principal foliação metamórfica a oeste do Rio do Oliveira. A seta tracejada clara indica os lineamentos de relevo negativo segundo N60-70E. As duas setas claras indicam a presença de cristas de relevo orientadas em torno de $\mathrm{N} 40 \mathrm{~W}$, provavelmente associadas a diques básicos mesozóicos.

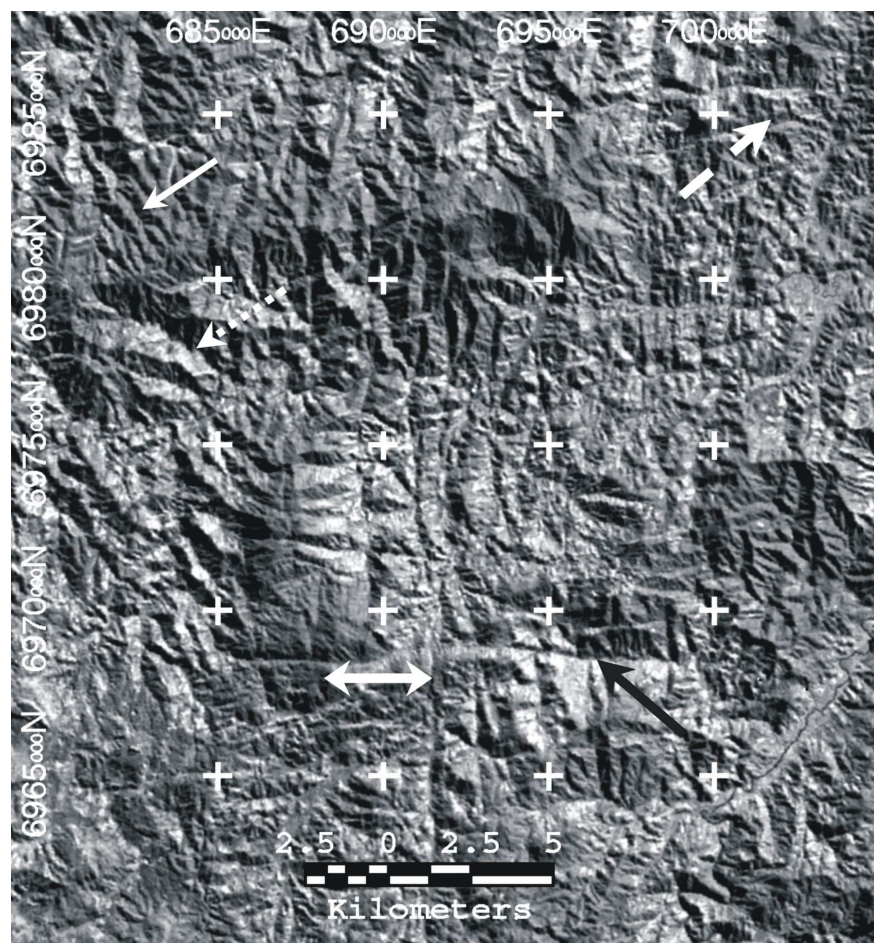

Figura 7 - Imagem PC1 da região do Cerro da Catinga, porção central da região estudada. As diferentes direções de lineamentos são indicadas da seguinte forma: N00-05E (seta clara dupla), E-W (seta escura), N40-45W (seta clara contínua); N70$85 \mathrm{~W}$ (seta clara pontilhada).

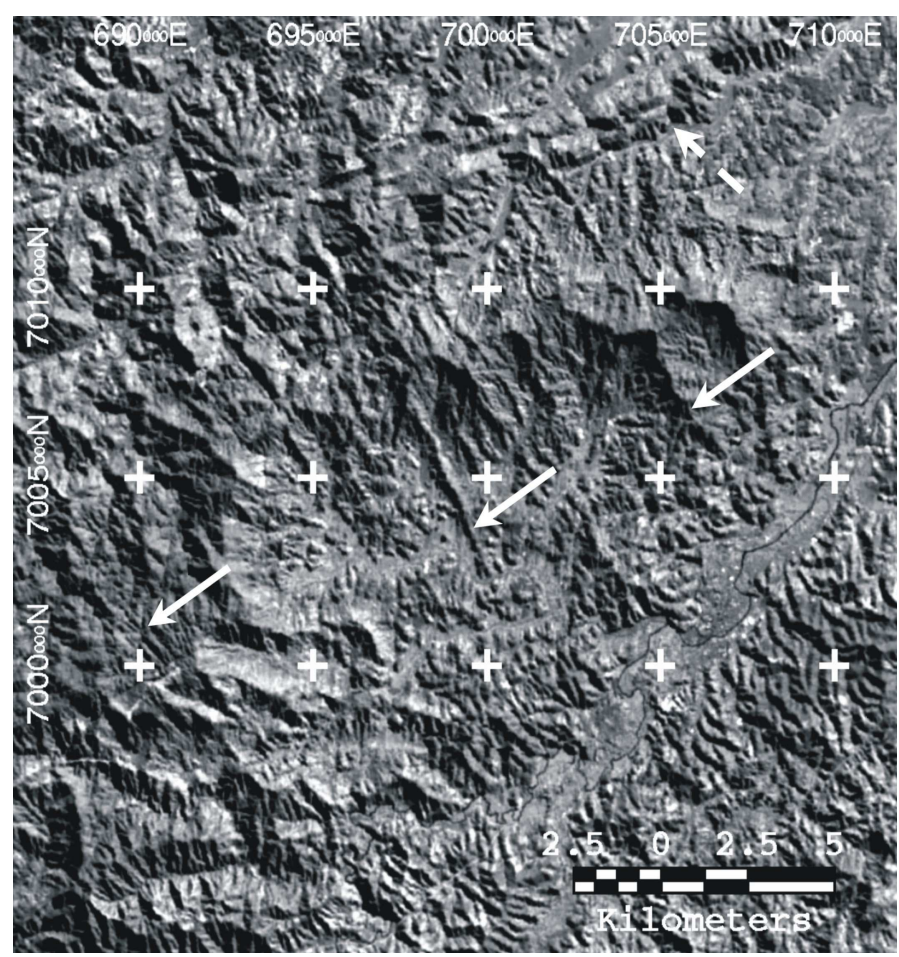

Figura 8 - Imagem PC1 da região próxima a Guabiruba. A seta contínua indica lineamentos de relevo positivo com direção N40W, associados preferencialmente a diques básicos mesozóicos. A seta tracejada indica lineamentos de relevo negativo associados à zona de cisalhamento Faixa Ribeirão da Prata.

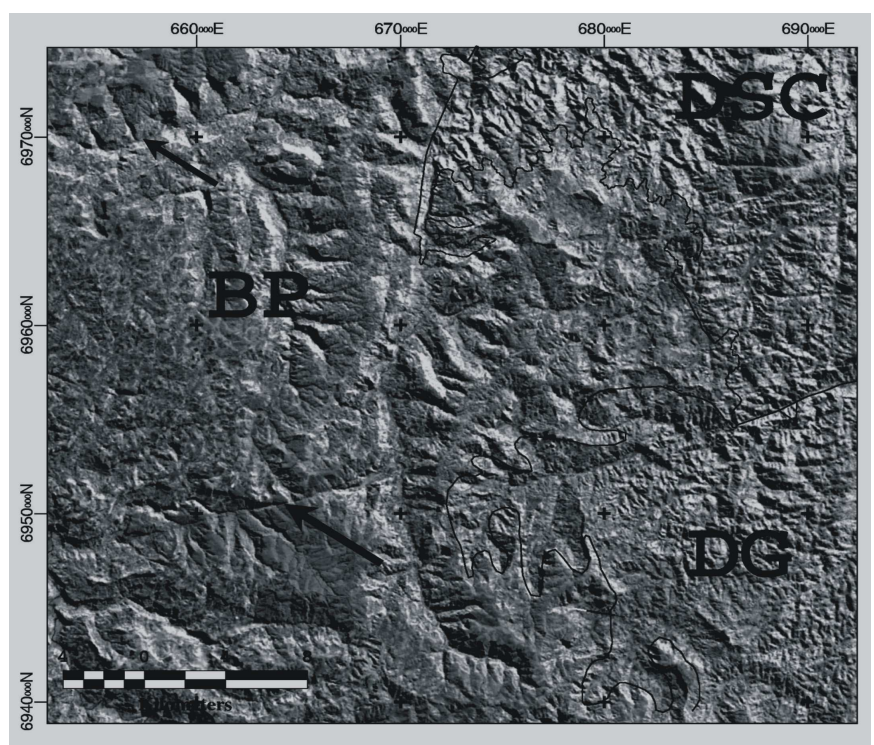

Figura 9 - Imagem PC1 mostrando o limite leste da Bacia do Paraná (BP), na porção $S W$ da região estudada (região de Alfredo Wagner). As setas mostram a presença de lineamentos de relevo negativo com direção $N 60-70 E$ indicando a continuidade das estruturas do embasamento sob a Bacia do Paraná. Domínios do Cinturão Dom Feliciano: Supra Crustal (DSC) e Granitóide (DG). 
atmosférico, efeito Compton e variações de altura; 5) magnetometria - medidas do campo magnético total em nT, com posterior correção da variação diurna e subtração do IGRF (International Geomagnetic Reference Field).

A análise estatística das 73.061 amostras da gamaespectrometria mostrou a presença de valores negativos em todos os quatro canais. Uma correção foi então aplicada, adicionando-se a cada canal um valor constante, de modo que o registro mínimo fosse de $0,1 \mathrm{cps}$.

Os dados originais foram interpolados pelo método da mínima curvatura (Briggs,1974), gerando células regulares espaçadas em $1 / 4$ do espaçamento médio das linhas de vôo. As malhas resultantes apresentaram componentes de ruído, dispostas invariavelmente segundo as linhas de vôo (N30W). A supressão de tais componentes foi implementada através da aplicação do filtro cosseno direcional. Após a remoção desses artefatos, as imagens gamaespectrométricas foram avaliadas em termos dos canais isolados (CT, eTh, eU e K), das razões eU/eTh, eTh/K e eU/K, e do parâmetro F de Gnojek \& Prichystal (1985), onde F=K(eU/eTh). Foram usadas também composições coloridas RGB dos canais K, eU e eTh e das razões.

A magnetometria foi inicialmente avaliada em termos da imagem do campo magnético corrigido do IGRF. Em seguida, os dados foram processados no sentido de detalhar as estruturas magnéticas rasas, correlacionando-as com as feições geológicas regionais e lineamentos extraídos das imagens LANDSAT/TM. Para isso, foi utilizada primeiramente a imagem do campo magnético removido o IGRF e a primeira derivada vertical. Em seguida, foi avaliada a imagem do sinal analítico (Nabighian 1972, Hsu et al. 1996, 1998), a qual serve para demarcar o limite dos corpos e estruturas, independente das direções de magnetização e do campo geomagnético (Milligan \& Gunn 1997). Para esta função, todos os corpos com a mesma geometria apresentam o mesmo sinal analítico, implicando que a amplitude do sinal analítico de ordem zero (simples) tende a centrar a forma das anomalias diretamente sobre os corpos causadores. A fase de ordem zero é especialmente utilizada para delinear fontes magnéticas rasas, sendo genericamente definida pelo quociente da primeira derivada vertical pelo gradiente horizontal. O gradiente horizontal de ordem zero é o vetor resultante da combinação das primeiras derivadas horizontais e indica mudanças abruptas do campo magnético, facilitando o mapeamento de estruturas magnéticas e contatos entre corpos.

Resultados A interpretação das imagens gamaespectrométricas, frente às principais feições litoestruturais do EPOSC, forneceu os seguintes resultados: 1) estabelecimento da associação de alguns lineamentos com a zona de cisalhamento da Faixa Ribeirão da Prata (Figs. 10A e 10B); 2) identificação de lineamentos relacionados às zonas de cisalhamento internas ao DSC (Fig. 10A); 3) registro de elevadas contagens nos canais eTh e $\mathrm{K}$ vinculadas à área de ocorrência do batólito Valsungana (forte anomalia de direção NE na porção central da figura 10A); 4) em todas as imagens aerogamaespectrométricas analisadas, a porção central do batólito Valsungana (Fig. 10A) aparece segmentada em duas porções distintas, aparentemente devido a um cisalhamento sinistral de direção NS presente nessa região; 5) valores muito baixos da razão U/Th do batólito Valsungana (Fig. 10C); 6) baixas contagens em toda a região de exposição das rochas vulcano-sedimentares do GCB (DSC); 7) caracterização do domínio granitóide (DG) através de elevadas contagens dos canais Th, U e, mais localmente, de The $\mathrm{K}$ (Fig. 10A); 8) delineamento de uma anomalia nos canais de The
$\mathrm{K}$, de forma alongada segundo a direção N05E, na porção SE da imagem, correspondente a um dos granitóides intrusivos no DG (Fig. 10A); 9) discriminação dos granitóides do DSC, onde se observa um enriquecimento de $\mathrm{K}$ nos corpos setentrionais (Figs. 10A,C, D); 10) enriquecimento de $\mathrm{K}$ de alguns corpos do Domínio Granitóide (DG-Fig. 10D), em sua maioria aparentemente controlados pela zona de cisalhamento Major Gercino; 11) definição de áreas com altas contagens em várias regiões dos domínios DSC e DG; 12) discriminação de regiões enriquecidas em K e U em relação ao Th (Figuras 10C e 10D), reveladas pela análise combinada das imagens da razão U/Th e do parâmetro $F$.

Os resultados do processamento e da interpretação dos dados magnetométricos são apresentados na Figura 11, à qual foram superpostos os principais domínios tectônicos do Cinturão Dom Feliciano(CDF). A Figura 11A, relativa ao campo magnético removido o IGRF, mostra boa correlação com os principais limites dos domínios tectônicos, como pode-se observar na interface DF/DS, através da zona de cisalhamento Faixa Ribeirão da Prata (ZCFRP). Também é perceptível o delineamento da zona de cisalhamento Ribeirão do Ouro (ZCRO) no contexto do DSC, assim como sua continuidade para SW e provável bifurcação para NE.

A assinatura geofísica da zona de cisalhamento Major Gercino (ZCMG) exibe duas descontinuidades magnéticas no seu segmento central, sendo aquela mais a NW coincidente com o limite entre o DSC e o DG, enquanto a situada a SE representa aproximadamente o limite meridional da faixa milonítica da zona de cisalhamento. O processamento do tipo "continuação para cima" indica a expressão destas zonas de cisalhamento em sub-superficie. A figura $11 \mathrm{~B}$ mostra o mapa da primeira derivada vertical ressaltando fontes mais rasas, exibindo em detalhe o padrão estrutural magnético da área.

A imagem da fase do sinal analítico de ordem zero (Fig. 11C) visou realçar as fontes rasas, gerando um mapa de lineamentos magnéticos (Fig. 11D). Nota-se que a maioria dos lineamentos coincide com a estruturação regional (NE-SW), refletindo maior contraste de susceptibilidade magnética no âmbito do CDF. A quase ausência de anomalias magnéticas nas outras direções, bem definidas nas imagens LANDSAT (NS-N5E, N40-45W e N75-85W), pode ser devido a natureza rúptil das estruturas que originaram esses lineamentos, desenvolvidas em meios magnéticos já estabelecidos. Outra possibilidade é que a conjunção entre a direção das linhas de vôo (N30W) e a aplicação da filtragem direcional para a remoção do ruído possa ter mascarado tais estruturas.

Finalmente, foi feita a análise integrada dos diferentes tipos de dados aerogeofísicos para caracterização das feições litoestruturais do CDF. A figura 12 mostra a integração dos dados gamaespectrométricas (eTh) e magnetométricas (fase do sinal analítico). Nessa figura, o pseudo-relevo é dado pela fase do sinal analítico sobreposto pelo canal do tório em tons coloridos. As feições mais marcantes observadas são: 1) a forma NE balizada pela forte estruturação de mesma direção e elevadas contagens na região do batólito Valsungana; 2) a expressiva estruturação N60-70E impressa na variável fase do sinal analítico, correspondendo, em parte, às principais zonas de cisalhamento que limitam os domínios do CDF e também internamente a este; 3 ) a continuação da estruturação NE por sob a Bacia do Paraná e pela região que adentra o oceano Atlântico.

A figura 13 mostra a integração da PC1 da imagem LANDSAT/ TM com os dados gamaespectrométricos, onde se observa a porção leste do batólito Valsungana (elevadas contagens em eTh) e as litologias do GCB (baixas contagens), destacando-se a relação 

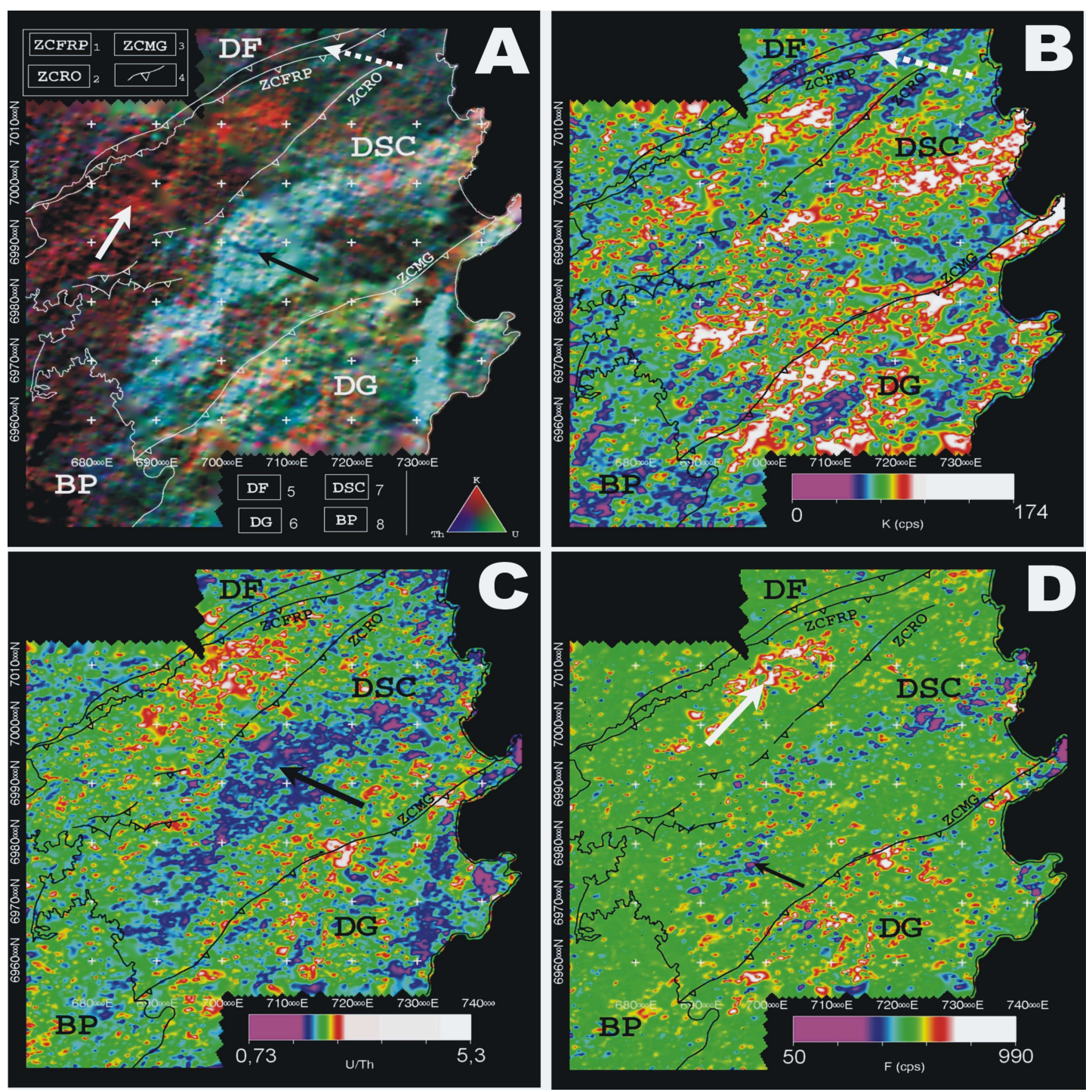

Figura 10 - Imagens gamaespectrométricas do Cinturão Dom Feliciano. Composição colorida RGB-KUTh (10A), do potássio (10B), da razão U/Th (10C) e do parâmetro F (10D). Em destaque, altas anomalias de K (seta clara cheia); anomalias associadas ao granitóide Valsungana (seta escura cheia); seta pontilhada: ZCFRP. Zonas de cisalhamento: Faixa Ribeirão da Prata (ZCFRP-1), Ribeirão do Ouro (ZCRO- 2), Major Gercino (ZCMG-3); Empurrões (4); Cinturão Dom Feliciano, dominios Foreland (DF-5), Granitóide (DG-6), Supracrustal (DSC-7); Bacia do Paraná (BP-8).

entre a forma do batólito e a grande concentração de lineamentos dispostos segundo N60-70E. Em ambos os casos, a superposição de informações de naturezas distintas fornece resultados que auxiliam na caracterização lito-estrutural da região.

CONSIDERAÇÕES FINAIS O trabalho demonstra a correlação entre as informações geológicas e as de sensoriamento remoto, mesmo considerando a limitada resolução destas últimas. A análise das imagens LANDSAT permite inferir a relação entre os lineamentos identificados e as estruturas geradas preferencialmente durante a orogênese Rio Doce $(\sim 530 \mathrm{Ma})$, processo este ligado à evolução do Cinturão Dom Feliciano e de seu antepaís (Cráton Luis Alves). Neste contexto, uma variada gama de estruturas associadas ao esforço compressivo então vigente $(\sim \mathrm{N} 45 \mathrm{~W})$ estaria hoje refletida nas principais direções de lineamentos observadas nas imagens LANDSAT-5/TM. Sugere-se um teste para o modelo aqui proposto, por meio da realização de análise litoestrutural e cinemática, levando em conta parâmetros geocronológicos e considerando locais específicos contendo os diferentes intervalos direcionais encontrados.

A hipótese de que as estruturas geradas durante as orogêneses Brasiliana e Rio Doce tenham continuidade na região atualmente coberta pela Bacia do Paraná foi corroborada pelos lineamentos identificados na pilha sedimentar em questão. Dentre esses lineamentos, destacam-se aqueles situados nos intervalos N60-70E, N00-05E e N70-80W. Observou-se, ainda, uma boa relação espacial entre feições lito-estruturais (fraturamento e magmatismo), geradas durante o rifteamento Mesozóico, e as prováveis estruturas decorrentes da deformação vigente durante a orogênese Cambriana. Neste contexto, os lineamentos do intervalo N40-45W 

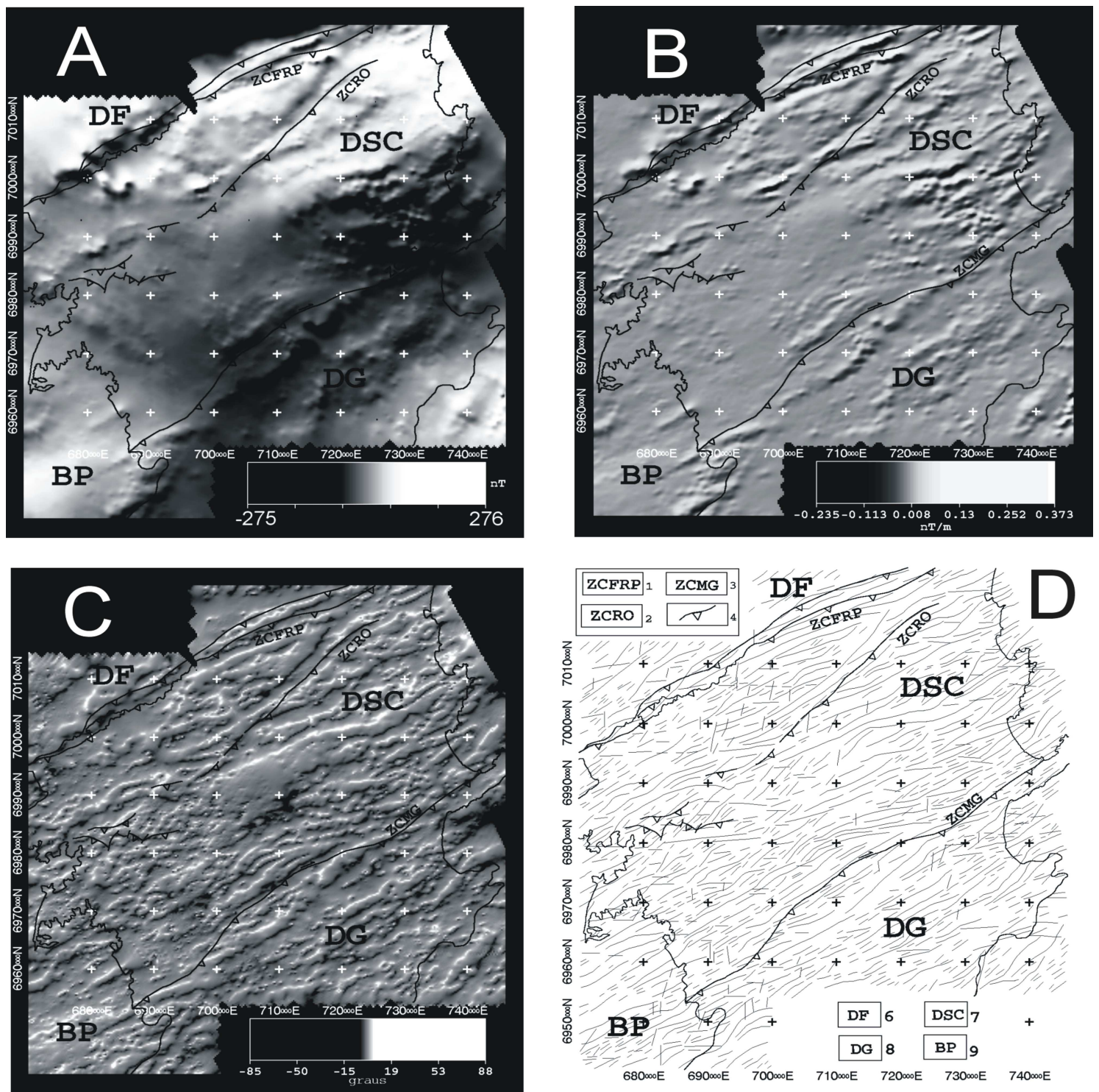

Figura 11 - Imagens aeromagnetométricas com os principais domínios tectônicos do Cinturão Dom Feliciano: campo magnético residual (11A); primeira derivada vertical (11B); fase do sinal analítico (11C); principais lineamentos magnéticos extraidos da imagem anterior (11D). Os demais itens da legenda constam da Figura 10.

são aproximadamente paralelos ao enxame de diques básicos do Arco de Ponta Grossa. Os lineamentos segundo N00-10E são concordantes com a direção dos diques básicos e das mineralizações de fluorita com barita, situadas a sul da região estudada. Tais intervalos direcionais (NS-10E e N40-45W) correspondem, respectivamente, aos braços abortado e evoluído da grande junção tríplice mesozóica ocorrida na porção meridional do Brasil.

A exemplo das imagens LANDSAT, as informações aerogeofísicas exibem feições que podem ser utilizadas na caracterização da geologia do EPOSC. Devem ser destacadas a expressão magnética das zonas de cisalhamento limítrofes do CDF e o contraste entre valores radiométricos existentes entre granitóides (elevados) e as supracrustais (baixos) pertencentes ao GCB. Dentre os granitóides presentes no domínio DSC, aqueles situados próximo à ZCFRP são anomalamente enriquecidos em potássio, o mesmo ocorrendo com algumas regiões dentro do DG. Futuramente deve ser dada atenção especial a esses enriquecimentos, uma vez que anomalias positivas de potássio associadas a granitóides podem estar associadas a mineralizações auríferas, cuja ocorrência é esparsamente conhecida na região.

Agradecimentos À CPRM (Companhia de Pesquisa de Recursos Minerais) pela cessão dos dados aerogeofísicos. N. A. Castro agradece também a CAPES e FAPESP pelo apoio financeiro. Aos revisores da $\mathrm{RBG}$ pelas sugestões ao manuscrito. 


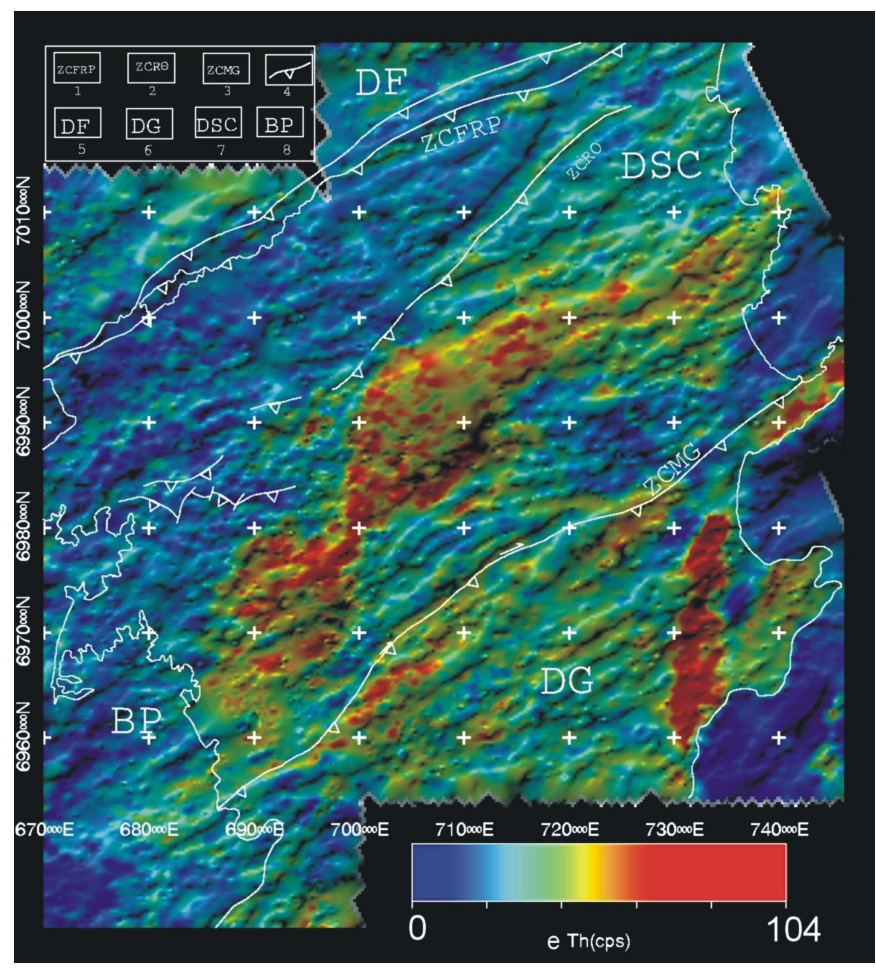

Figura 12 - Imagem da integração da fase do sinal analítico em relevo e do canal do Th em pseudocor, na área correspondente ao Cinturão Dom Feliciano. Os demais itens da legenda constam da Figura 14 ???????????.

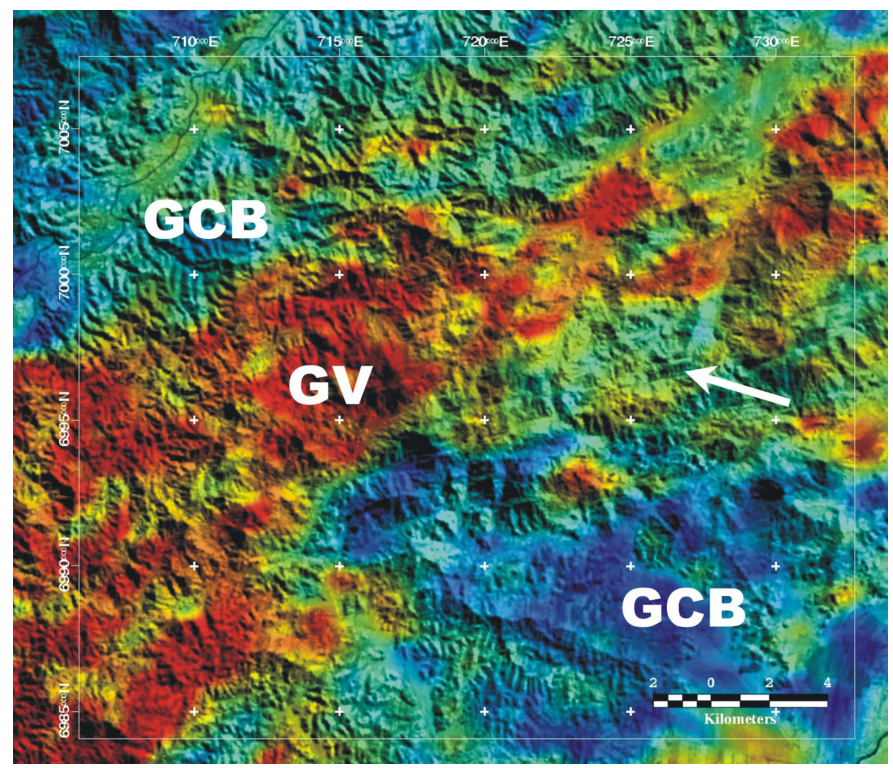

Figura 13 - Imagem PC1 da imagem LANDSAT/TM combinada ao canal Th em tons coloridos (azul; baixas contagens; vermelho: altas contagens) da porção centro-leste do granitóide Valsungana (BV) e suas encaixantes (GCB). A seta clara indica a expressiva concentração de lineamentos N60-70E.

\section{Referências}

Almeida F.F.M. 1986. Distribuição regional e relações tectônicas do magmatismo pós-Paleozóico no Brasil. Rev. Bras. Geoc., 16:325349.

Amaral G. 1994. Métodos para a obtenção de informação estrutural em produtos de sensoriamento remoto. Cadernos IG-UNICAMP, 4:98111.

Basei M.A.S. 1985. O Cinturão Dom Feliciano em Santa Catarina. Instituto de Geociências, Universidade de São Paulo, São Paulo, Tese de Doutorado, 190p.

Basei M.A.S., Siga Jr. O., Cordani U.G., Sato K., Lima P.S. 1999. The magmatism of the Itajaí Basin, SC, Southern Brazil, and its importance to define the Proterozoic-Phanerozoic limit. In: South American Symposium on Isotope Geology, 2, Actas, Cordoba, Argentine, 278-290.

Basei M.A.S., Siga Jr. O., Masquelin H., Harara O.M., Reis Neto J.M., Preciozzi F.P. 2000. The Dom Feliciano Belt of Brasil and Uruguay and its foreland domain, the Rio de La Plata craton: framework, tectonic evolution and correlation with similar provinces of southwestern Africa. In: U.G Cordani, E.J. Milani, A. Thomaz Filho, D.A. Campos (eds.) Tectonic Evolution of South America. Rio de Janeiro, ed. Esp. XXXI International Geological Congress, Rio de Janeiro-Brasil, p. 311-334.

Briggs I.C. 1974. Machine contouring using minimum curvature. Geophysics, 39:80-91.

Caldasso A.L.S., Camazzoto E., Rangrab G.E., Silva M.A.S. 1988. Os granitóides Valsungana, Guabiruba e Faxinal no contexto dos metamórficos do Complexo Brusque, SC. In: SBG, Congr. Bras. Geol., 35, Belém, Anais, 3:1104-1116.
Caldasso A.L.S., Krebs A.S.J., Silva M.A.S. 1994a. Geologia da Folha Botuverá (SG.22-Z-D-I-2), Estado de Santa Catarina. In: SBG, Congr. Bras. Geol., 38, Balneário de Camboriú, Anais, 2:78-79.

Caldasso A.L.S., Krebs A.S.J., Silva M.A.S. 1994b. Geologia da Folha Brusque (SG.22-Z-D-II-1), Estado de Santa Catarina. In: SBG, Congr. Bras. Geol., 38, Balneário de Camboriú, Anais, 2:79.

Campos Neto M.C \& Figueiredo M.C.H. 1995. The Rio Doce Orogny, southeastern Brazil. J. Sou. Am. Earth Sci., 8:143-162.

Carvalho P.F. \& Pinto E.A. 1938. Reconhecimento geológico no Estado de Santa Catarina. Rio de Janeiro: DGM/DNPM,. 30p. (Boletim 92).

Castro N.A. 1997. Contribuição ao conhecimento geológicometalogenético associado aos granitóides intrusivos no Grupo Brusque (SC) com base em informações geológicas, aerogamaespectrométricas e LANDSAT TTM-5. Dissertação de Mestrado, UNICAMP, Campinas, 139 p.

Castro N.A. Basei M.A.S., Crósta A.P. 1997. Catinga suite: W-(Sn-Mo) specialized granitoids in the Brusque Group, Neoproterozoic of the State Santa Catarina, southern Brazil. In: SBG, II ISGAM, Salvador, Anais, 40-41.

Conceição J.C. de Jesus, Zalán P.V., Wolff S. 1988. Mecanismo, evolução e cronologia do rift sul-Atlântico. Bol. Geociências da PETROBRAS, Rio de Janeiro, 2(2/4):255-265.

Cordani U.G., Neves B.B., Fuck R.A., Porto R., Thomaz Filho A., Cunha F.M.B. 1984. Estudo preliminar de integração do Précambriano com os eventos tectônicos das bacias sedimentares brasileiras. Petrobras/Cenpes/Sintep., (Cienc. Tec. Petroleo, Seç. Expl. Petroleo), 70p. 
Crósta A.P. 1993. Processamento digital de imagens de Sensoriamento Remoto. IG-UNICAMP, Campinas, 170p.

Drury S.A. 2001. Image interpretation in Geology. 3 ed., Blackwell, London, 290p.

Ferreira A.C. \& Almeida T.I.R. 1989. Tectônica transcorrente e imagens TM-Landsat aplicadas à prospecção de fluorita e barita em Santa Catarina. Rev. Bras. Geoc., 19:207-223.

Ferreira F.J.F. 1982. Integração de dados aeromagnéticos e geológicos: configuração e evolução do Arco de Ponta Grossa. Dissertação de Mestrado, IGC-USP, São Paulo, 169p.

Fragoso Cesar A.R.S. 1980. O Cráton do Rio de La Plata e o Cinturão Dom Feliciao no Escudo Uruguaio-Sul Riograndense. In: SBG, Congr. Bras. Geol., 31, Camboriú, Anais, 5:2879-2891.

GEOFOTO. 1978. Projeto Serra do Mar Sul, Relatório Final. Rio de Janeiro, GEOFOTO S.A., 48p.

Gnojek I. \& Prichystal A. 1985. A new zinc mineralization detected by airbone gamma-ray spectrometry in northern Moravia (Czechoslovakia). Geoexploration, 23:491-502.

Gunn P.J., Maidment D., Milligan P.R. 1997. Interpreting aeromagnetic data in areas of limited outcrop. AGSO-J. Austral. Geol. Geoph., 17:175-186.

Hallinan S.E. \& Mantovani M.M.S. 1993. Structural framework of the Southern Brasilian Shield: the perspective from the gravity models. SBGF, III Intern. Geophyisical Congr., Anais, Rio de Janeiro, Anais, 2:1078-1083.

Harding T.P. 1974. Petroleum traps associated with wrench faults. $A A P G$ Bulletim, 58:1290-1304.

Hartman L.A., Silva L.C., Remus M.V.D., Leite J.A.D., Philipp R.P. 1998. Evolução geotectônica do sul do Brasil e Uruguai entre 3.3GA e 470Ma. In: Cogr. Uruguaio de Geologia, 2, Punta del Este, Actas, 277-284.

Horsfall K.R. 1997. Airbone magnetic and gamma-ray data acquisition. AGSO-J. Austral. Geol. Geoph., 17:23-30.

Hsu S.K., Sibuet J.C., Shyu C.T. 1996. High-resolution detection of geologic boundaries from potential field anomalies: an enhanced analytic signal. Geophysics, 61:373-386.

Hsu S.K., Coppens D., Shyu C.T. 1998. Depht to magnetic source using the generalized analytical signal. Geophysics, 63:1947-1957.

Liu C.C. 1984. Análise estrutural de lineamentos em imagens de sensoriamento remoto: aplicação ao Estado do Rio de Janeiro. Inst. Geoc., Universidade de São Paulo, São Paulo, Tese de Doutorado, $157 \mathrm{p}$.

Luyendyk A.P.J. 1997. Processing of airbone magnetic data. AGSO-J. Austral. Geol. Geoph., 17:31-38.

Mantovani M.S.M., Hawkesworth C.J., Basei M.A.S. 1987. Nd and Pb isotope bearing on the crustal evolution of southeastern Brazil. Rev. Bras. Geoc., 17:263-268.

MacLeod I.N. \& Dobush T.M. 2000. Geophysics - More than numbers, process and presentation of geophysical data. Oasis Montaj v. 5.0, Technical Notes, $15 \mathrm{p}$.

Milani E.J. \& Thomaz Filho A. 2000. Sedimentary basins of the South America. In: U.G Cordani, E.J. Milani, A. Thomaz Filho, D.A. Campos (eds.) Tectonic Evolution of South America. Rio de Janeiro, ed. Esp. XXXI International Geological Congress, Rio de Janeiro-
Brasil, p. 389-449.

Milligan P.R. \& Gunn P.J. 1997. Enhancement and presentation of airbone geophysical data. AGSO-J. Austral. Geol. Geoph., 17:63-76.

Minty B.R.S., Luyendyk A.P.J., Brodie R.C. 1997. Calibration and data processing for airbone gamma-ray spectrometry. AGSO-J. Austral. Geol. Geoph., 17:51-62.

Nabighian M.N. 1972. The analytic signal of two-dimensional magnetic bodies with poligonal cross-section: its properties and use for autamated anomaly interpretation. Geophysics, 37:507-517.

Passarelli C.R. 1996. Análise estrutural e caracterização do magmatismo da zona de cisalhamento Major Gercino, SC. Inst. Geociências, Universidade de São Paulo, São Paulo, Dissertação de Mestrado, 179p.

Renne P.R., Ernesto M., Pacca I.G., Coe R.S., Glen J.M, Prévot M., Perrin M. 1992. The age of Paraná flood volcanism, rifting of Gondwanaland, and the JurassicCretaceus Bondary. Science, 258:975978.

Reeves C.V., Reford S.W., Milligan P.R. 1997. Airbone geophysics: old methods, new images. In: A.G. Gubins (Ed.) Proccedings of Exploration 97, 13-30.

Rostirolla S.P., Soares P.C., Alkmin F.F. 1992. Análise estrutural da tectônica deformadora da Bacia de Itajaí, Estado de Santa Catarina, Brasil. Bol. Geoc. PETROBRAS, Rio de Janeiro, 6(3/4):123-147.

Siga Jr. O., Basei M.A.S., Kawashita K. 1990. Perfil térmico K-Ar através do Maciço de Joinville (PR e SC) e do Cinturão Dom Feliciano (SC) - Implicações tectônicas. In: SBG, Congr. Bras. Geol., 36, Natal, Anais, 2773-2785.

Soares P.C. 1988. Tectônica colisional em torno de bloco Paraná, Brasil. In: Congr. Latino-Americano Geologia, 7, Pará,. Anais 1:63-79.

Soares P.C. 1992. Tectônica sinsedimentar cíclica na Bacia do ParanáControles. Dep. Geologia Universidade Federal do Paraná, Curitiba, $131 \mathrm{p}$.

Soares P.C. \& Fiori A.P. 1976. Lógica e sistemática na análise e interpretação de fotografias aéreas em geologia. Notícias Geomorfológicas, Campinas, 16(32): 71-104.

Szatimari P. \& Milani E.J. 1999. Microplate rotation in northeast Brazil during South Atlantic rifting: analogies with the Sinai microplate. Geology, 27:1115-1118.

Thomas G.E. 1974. Lineament-Block tectonics: Williston-Blood Creek basin. AA Geologists Bulletim, 58:1305-1322.

Trainini D.R., Dias A.A., Krebs A.S.J., Souza E.C., Capeletti I., Toniolo J.A., Silva L.C. da, Silva M.A.S. 1978. Projeto Vidal Ramos-Biguaçu. Porto Alegre: DNPM/CPRM, 303p.

Trompette R. 1997. Neoproterozoic ( 600 Ma) aggregation of western Gondwana: a tentative scenario. Prec. Res., 82:101-112.

Yeates A.N., Wyatt B.W., Tucker D.H. 1982. Aplication of gamma-ray spectrometry to prospecting for tin and tungsten granites, particularly within the Laclan Fold Belt-New South Wales. Econ. Geol., 77:1725-1738.

Manuscrito SR-22

Recebido em 17 de novembro de 2002

Revisão dos autores em 06 de março de 2003

Revisão aceita em 01 de abril de 2003 